\title{
RESEARCH
}

Open Access

\section{miR-155 and miR-146a collectively regulate meningitic Escherichia coli infection- mediated neuroinflammatory responses}

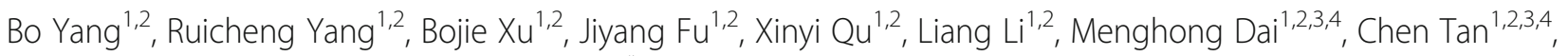
Huanchun Chen ${ }^{1,2,3,4}$ and Xiangru Wang ${ }^{1,2,3,4^{*}}$ (i)

\begin{abstract}
Background: Escherichia coli is the most common Gram-negative bacterium causing meningitis, and E. coli meningitis is associated with high mortality and morbidity throughout the world. Our previous study showed that E. coli can colonize the brain and cause neuroinflammation. Increasing evidence supports the involvement of miRNAs as key regulators of neuroinflammation. However, it is not clear whether these molecules participate in the regulation of meningitic E. coli-mediated neuroinflammation.

Methods: The levels of miR-155 and miR-146a, as well as their precursors, in E. coli-infected astrocytes were measured using quantitative real-time PCR (qPCR). Overexpression and knockdown studies of miR-155 and miR146a were performed to observe the effects on bacterial loads, cytokines, chemokines, and NF-KB signaling pathways. Bioinformatics methods were utilized to predict the target genes, and these target genes were validated using qPCR, Western blotting, and luciferase reporter system. In vivo knockdown of miR-155 and miR-146a was carried out to observe the effects on bacterial loads, inflammatory genes, astrocyte activation, microglia activation, and survival in a mouse model.

(Continued on next page)
\end{abstract}

\footnotetext{
* Correspondence: wangxr228@mail.hzau.edu.cn

'State Key Laboratory of Agricultural Microbiology, College of Veterinary

Medicine, Huazhong Agricultural University, Wuhan, Hubei, China

${ }^{2}$ Key Laboratory of Preventive Veterinary Medicine in Hubei Province, The

Cooperative Innovation Center for Sustainable Pig Production, Wuhan, Hubei,

China

Full list of author information is available at the end of the article
}

(c) The Author(s). 2021 Open Access This article is licensed under a Creative Commons Attribution 4.0 International License, which permits use, sharing, adaptation, distribution and reproduction in any medium or format, as long as you give appropriate credit to the original author(s) and the source, provide a link to the Creative Commons licence, and indicate if changes were made. The images or other third party material in this article are included in the article's Creative Commons licence, unless indicated otherwise in a credit line to the material. If material is not included in the article's Creative Commons licence and your intended use is not permitted by statutory regulation or exceeds the permitted use, you will need to obtain permission directly from the copyright holder. To view a copy of this licence, visit http://creativecommons.org/licenses/by/4.0/ The Creative Commons Public Domain Dedication waiver (http://creativecommons.org/publicdomain/zero/1.0/) applies to the data made available in this article, unless otherwise stated in a credit line to the data. 
(Continued from previous page)

Results: The levels of miR-155, miR-146a, and their precursors were significantly increased in astrocytes during $E$. coli infection. miR-155 and miR-146a were induced by the NF-kB-p65 signaling pathway upon infection.

Overexpressing and inhibiting miR-155 and miR-146a in astrocytes did not affect the bacterial loads. Further, the in vitro overexpression of miR-155 and miR-146a suppressed the E. coli-induced inflammatory response, whereas the inhibition of miR-155 and miR-146a enhanced it. Mechanistically, miR-155 inhibited TAB2, and miR-146a targeted IRAK1 and TRAF6; therefore, they functioned collaboratively to modulate TLR-mediated NF-KB signaling. In addition, both miR-155 and miR-146a could regulate the EGFR-NF-kB signaling pathway. Finally, the in vivo suppression of E. coli-induced miR-155 and miR-146a further promoted the production of inflammatory cytokines, aggravated astrocyte and microglia activation, and decreased mouse survival time, without affecting the bacterial loads in the blood and brain.

Conclusions: E. coli infection induced miR-155 and miR-146a, which collectively regulated bacteria-triggered neuroinflammatory responses through negative feedback regulation involving the TLR-mediated NF-KB and EGFRNF-KB signaling pathways, thus protecting the central nervous system from further neuroinflammatory damage.

Keywords: miR-155, miR-146a, Escherichia coli, Astrocytes, Neuroinflammation

\section{Background}

Bacterial meningitis remains an important cause of mortality and morbidity worldwide despite advances in antimicrobial chemotherapy and supportive care. The mortality and morbidity vary depending on the geographic location and patient age, and those living in lowincome countries and newborns have a higher risk of mortality and morbidity [1-3]. Escherichia coli is the most common Gram-negative bacillary organism that causes meningitis, in particular during the neonatal period [4]. E. coli entry into the central nervous system (CNS) elicits the release of many factors from host cells including microglia, astrocytes, and infiltrating inflammatory cells, which exacerbates host cellular responses, leading to neuronal injury. Among all host cells, astrocytes are now emerging as those that can recruit, instruct, and retain leukocytes at sites of CNS insults [5]. Astrocytes can produce a variety of pro-inflammatory molecules such as cytokines, chemokines, growth factors, and small molecules. Our previous study showed that E. coli can colonize the brain and cause neuroinflammation [6]. A proper inflammatory response is beneficial to the host, whereas an excessive inflammatory response might result in damage. Therefore, the duration and intensity of the inflammatory response are vital to the host and should be maintained at an appropriate level.

MicroRNAs (miRNAs) play a vital role in posttranscriptional gene regulation by targeting 3'-untranslated regions (UTRs), which leads to translational tuning, repression, or degradation [7]. An increasing number of investigations has proved that miRNAs are important regulators of neuroinflammation. miR-155 and miR$146 \mathrm{a}$ are the most widely characterized miRNAs that modulate different stages of the innate immune response during inflammation and infection. Since each miRNA has multiple targets, a single miRNA could modulate a large number of proteins and thus can exert diverse effects in different situations. It has been widely reported that miR-155 contributes to pro-inflammatory signaling cascades by inhibiting SHIP-1 [8] and SOCS1 [9]; however, miR-155 also functions to deactivate the proinflammatory response by targeting IRF8 [10] and TAB2 [11]. miR-146a was initially reported to be upregulated in macrophages in response to the Toll-like receptor (TLR)-mediated NF- $\mathrm{BB}$ signaling pathway [12]. miR$146 \mathrm{a}$ is an important negative regulator of innate immune activation that functions by regulating TRAF6 and IRAK1 [12, 13]. However, given the redundant and highly cell-specific effects mediated by microRNA species, the precise functional implications of miR-155 and miR-146a expression during meningitic $E$. coli infection remain obscure.

In the current study, we demonstrated that the meningitic infection of astrocytes by $E$. coli could significantly upregulate miR-155 and miR-146a through NF-kB signaling, which in turn negatively regulated bacteriatriggered pro-inflammatory cytokine and chemokine production via TLR-mediated NF- $\mathrm{kB}$ signaling and the EGFR-NF- $\mathrm{B}$ pathway. In vivo treatment of $E$. coli-infected mice with antagomir-155 or antagomir-146a augmented overall neuroinflammation and decreased survival time. These findings reveal that miR-155 and miR-146a are important inflammatory regulators of NF$\mathrm{\kappa B}$ activation during meningitic $E$. coli infections that function by inducing negative feedback with respect to TLR-mediated and EGFR-mediated immunity.

\section{Materials and methods}

\section{Bacterial strain}

The meningitic E. coli strain PCN033, which is a highly virulent cerebrospinal fluid isolate isolated in China in 
2006 [14], was cultured aerobically in Luria-Bertani (LB) broth or on LB plates at $37^{\circ} \mathrm{C}$. This strain was shown to be able to cause host blood-brain barrier (BBB) disruption and severe neuroinflammation in vitro and in vivo [6].

\section{Cell culture and infection}

The human astrocyte cell line U251 (a kind gift from Prof. Shengbo Cao in Huazhong Agricultural University, Wuhan, China) and HEK-293T cells (ATCC ${ }^{\circ}$ CRL$\left.3216^{\mathrm{m}}\right)$ were cultured in Dulbecco's modified Eagle's medium containing $10 \%$ heat-inactivated fetal bovine serum in a $37{ }^{\circ} \mathrm{C}$ incubator with a $5 \% \mathrm{CO}_{2}$ atmosphere. U251 cells were cultured in $10-\mathrm{cm}$ dishes until monolayer confluence. Confluent cells were washed three times with phosphate-buffered saline (PBS) and starved in serum-free medium for $16-18 \mathrm{~h}$ prior to infection. PCN033 overnight cultures were resuspended in serumfree medium and added to the starved U251 monolayer cells at a multiplicity of infection (MOI) of 10 .

\section{Reagents}

The anti-TAB2 antibody was purchased from Proteintech (Chicago, IL, USA). Anti-IRAK1 and anti-TRAF6 antibodies were from Sigma-Aldrich (St. Louis, MO, USA). Anti- $\beta$-actin antibody was from HuaAn Biotechnology Co., Ltd. (Hangzhou, China). Anti-NF-kB p65, antiphospho-p65, HRP-conjugated anti-rabbit IgG, and antimouse IgG were obtained from Cell Signaling Technology (Danvers, MA, USA). The transfection reagent jetPRIME was purchased from Polyplus Transfection (Illkirch, France). has-miR-155 and has-miR-146a mimics (doublestranded RNA oligonucleotides), inhibitors (singlestranded chemically modified oligonucleotides), and control oligonucleotides were commercially synthesized by GenePharma (Suzhou, China). Cholesterol-conjugated and chemically modified mmu-miR-155 inhibitors (antagomir-155) and mmu-miR-146a inhibitors (antagomir146a) were synthesized by GenePharma. The super electrochemiluminescence (ECL) kit was obtained from US Everbright Inc (Suzhou, China).

\section{Plasmid construction}

The 3' UTR sequences of target genes were amplified from U251 cDNA and cloned into the psiCheck-2 dualluciferase reporter vector (Promega Madison, WI, USA). The promoter sequences of miR-155 and miR-146a were cloned into pGL3-basic (Promega Madison). The sitespecific mutation plasmids were constructed by overlapping extension PCR. To construct the transcription factor expression vector, the coding regions of p65 were amplified from U251 cDNA and cloned into pCDNA3.1. All constructs were verified by sequencing.

\section{RNA interference}

Small interfering RNAs (siRNAs) siRNA-TAB2, siRNAIRAK1, siRNA-TRAF6, and the control siRNA were purchased from Gene Pharma. Transfection was performed with jetPRIME according to the manufacturer's instructions. Cells were transfected with $50 \mathrm{nM}$ of each siRNA.

\section{Transfection}

U251 cells and HEK-293T cells were plated in six-well plates and grown to $70 \%$ confluence. Cells were subsequently transfected with plasmids and/or RNAs using jetPRIME according to the manufacturer's instructions, followed by $24-48 \mathrm{~h}$ of incubation at $37^{\circ} \mathrm{C}$ with $5 \% \mathrm{CO}_{2}$.

\section{3' UTR luciferase reporter assays}

HEK-293T cells were co-transfected with $200 \mathrm{ng}$ psiCheck-2 target genes 3' UTR luciferase reporter plasmid or psiCheck-2 mutant target genes 3' UTR luciferase reporter plasmid, along with miRNA mimics or control (final concentration, $50 \mathrm{nM}$ ). After $24 \mathrm{~h}$, cells were collected and assayed for both firefly and Renilla luciferase activities using the Dual-Luciferase Reporter System following the manufacturer's instructions (Promega, Madison, WI, USA). The results were calculated as the ratio of Renilla luciferase activity to firefly luciferase activity and recorded as the mean + SD from three replicate wells.

\section{Promoter luciferase reporter assays}

HEK-293T cells were co-transfected with $200 \mathrm{ng}$ of fulllength or mutant promoter firefly luciferase reporter constructs and $10 \mathrm{ng}$ of Renilla luciferase vector (pRLTK), along with the transcription factor expression vector or control. Luciferase activities were determined with the Dual-Luciferase Reporter Assay System according to the manufacturer's protocol. The results were expressed as relative luciferase activity by normalizing firefly luciferase activity against Renilla luciferase activity and recorded as the mean + SD from three replicate wells.

\section{Animal infection and antagomir administration}

The 28-day-old SPF KM mice were obtained from the experimental animal center at China Three Gorges University (Hubei Province, China). Mice were randomly assigned to four groups as follows: control (PBS); antagomir controltreated and E. coli-infected group (antagomir-ctrl + PCN033); antagomir-155-treated and E. coli-infected (antagomir-155 + PCN033); and antagomir-146a-treated and $E$. coli-infected (antagomir-146a + PCN033). For the antagomir, $60 \mathrm{mg} / \mathrm{kg}$ body weight of the antagomir was injected through the tail vein. After $24 \mathrm{~h}$, mice were intravenously challenged with $1 \times 10^{7}$ CFUs of E. coli strain PCN033 or an equal volume of PBS. At $6 \mathrm{~h}$ post-infection, mice were sacrificed and blood was collected for quantitative circulating bacterial 
cultures. Subsequently, mice were perfused, and brain samples were collected and processed for further assays. For the in vivo colonization assay, brains were weighed, homogenized, and plated to determine the bacterial counts.

\section{RNA extraction and quantitative real-time PCR (qPCR)}

Total RNA was extracted using TRIzol ${ }^{\circ}$ Reagent according to the manufacturer's protocol. Following RNA extraction, $1 \mu \mathrm{g}$ of RNA was reverse transcribed into cDNA using the HiScript II Q RT SuperMix (Vazyme, Nanjing, China). Real-time PCR was performed with the MonAmp ${ }^{\text {tw }}$ SYBR Green qPCR Mix (RN04005M, Monad Biotech Co., Ltd, Wuhan, China) in accordance with the manufacturer's instructions. The PCR conditions included an initial step at $50{ }^{\circ} \mathrm{C}$ for $2 \mathrm{~min}$ and $95{ }^{\circ} \mathrm{C}$ for 10 $\mathrm{min}$, followed by 40 cycles of amplification and quantification $\left(95{ }^{\circ} \mathrm{C}\right.$ for $15 \mathrm{~s}, 60{ }^{\circ} \mathrm{C}$ for $\left.1 \mathrm{~min}\right)$. The expression of all mRNA targets was normalized to GAPDH or $\beta$ actin levels, and the miRNA expression was normalized to U6. Primers used for qPCR in this study are listed in Table 1 . The relative expression level was calculated by the $2^{-\Delta \Delta C T}$ method, and the results are presented as the mean + SD. Each assay was performed independently three times in triplicate.

\section{Western blotting}

Challenged U251 cells were lysed in RIPA buffer with a protease inhibitor cocktail (Sigma-Aldrich, USA), sonicated, and centrifuged at $12,000 \mathrm{rpm}$ for $10 \mathrm{~min}$ at $4{ }^{\circ} \mathrm{C}$. The protein concentration in the supernatant was measured using a BCA protein assay kit (Beyotime, China). Sodium dodecyl sulphate-polyacrylamide gel electrophoresis was performed, followed by protein transfer to polyvinylidene fluoride membranes using a Mini Trans-Blot Cell (Bio-Rad). Blots were probed with relevant antibodies, and the detection of proteins was conducted using ECL reagent. The densitometric analysis was performed using ImageJ software.

\section{Electrochemiluminescence $(\mathrm{ECL})$ assays}

Brain tissue samples from challenged mice were lysed in RIPA buffer (supplemented with protease inhibitor) and centrifuged at 12,000 rpm for $10 \mathrm{~min}$ to eliminate tissue debris. The supernatant was stored at $-80{ }^{\circ} \mathrm{C}$ and later used for the measurement of preselected cytokines and chemokines, including IL-1 $\beta$, IL-6, TNF- $\alpha$, MCP-1, and MIP-2 using the ECL V-Plex Proinflammatory Panel (mouse) kit (Meso Scale Discovery, Meso Scale Diagnostics, Rockville, MD, USA), following the manufacturer's instructions.

\section{Immunofluorescence microscopy}

U251 cells were transfected with miR-155, miR-146a, or miR-ctrl, and $24 \mathrm{~h}$ after transfection, cells were challenged with PCNO33 at an MOI of 10 for $3 \mathrm{~h}$, and cells were washed and fixed with $4 \%$ paraformaldehyde. The fixed cells were subsequently incubated with primary anti-p65 antibody and then with CY3-labeled goat antimouse IgG antibody. The plate was mounted and visualized using fluorescence microscopy.

Table 1 Primers used for $\mathrm{QPCR}$ in this study

\begin{tabular}{|c|c|c|c|}
\hline Gene & Forward $\left(5^{\prime}-3^{\prime}\right)$ & Reverse $\left(5^{\prime}-3^{\prime}\right)$ & Species \\
\hline IRAK1 & GCACCCACAACTTCTCGGAG & CACCGTGTTCCTCATCACCG & Human \\
\hline TRAF6 & TTGCCATGAAAAGATGCAGAGG & AGCCTGGGCCAACATTCTC & Human \\
\hline TAB2 & GCAGCAAAGGAACATCTAGCC & TGGACTGTTAAGTACAGGTGGA & Human \\
\hline EGFR & TGCCACCTGTGCCATCCA & ACCACCAGCAGCAAGAGGAG & Human \\
\hline GAPDH & TGCCTCCTGCACCACCAACT & CGCCTGCTTCACCACCTTC & Human \\
\hline MIR155HG & GCGAGCAGAGAATCTACCT & TCTAAGCCTCACAACAACCT & Human \\
\hline pri-mir146a & СTCCTCTGTCACCAAGTAA & ССТCTAACCTTCTGCCTAA & Human \\
\hline IL $1 \beta$ & ATGATGGCTTATTACAGTGGCAA & GTCGGAGATTCGTAGCTGGA & Human \\
\hline IL6 & ACTCACCTCTTCAGAACGAATTG & CCATCTITGGAAGGTTCAGGTTG & Human \\
\hline TNF-a & CGAGTGACAAGCCTGTAG & GGACCTGGGAGTAGATGA & Human \\
\hline MCP-1 & CAGCCAGATGCAATCAATGCC & TGGAATCCTGAACCCACTTCT & Human \\
\hline CXCL2 & AGTGTGAAGGTGAAGTCC & CTTCTGCCCATTCTTGAG & Human \\
\hline IL $1 \beta$ & GCAACTGTTCCTGAACTCAACT & ATCTITGGGGTCCGTCAACT & Murine \\
\hline IL6 & TTCCATCCAGTTGCCTTCT & AAGCCTCCGACTTGTGAA & Murine \\
\hline TNF-a & CCCTCACACTCAGATCATCTTCT & GCTACGACGTGGGCTACAG & Murine \\
\hline MCP-1 & TGTGAAGTTGACCCGTAA & TCCTACAGAAGTGCTTGAG & Murine \\
\hline CXCL2 & TGACTTCAAGAACATCCAGAG & CCTTGCCTITGTTCAGTATCT & Murine \\
\hline$\beta$-actin & GTCCCTCCTCTGATACCTTCCTC & CTGGCAGTGTCATTCACATCTTTCT & Murine \\
\hline
\end{tabular}


Brain samples were collected, fixed in $4 \%$ formaldehyde solution for over $24 \mathrm{~h}$, and embedded in paraffin. Sections were incubated overnight at $4{ }^{\circ} \mathrm{C}$ with primary antibodies against GFAP (glial fibrillary acidic protein) or IBA1 (ionized calcium-binding adaptor molecule 1). After washing, sections were incubated with appropriate secondary antibodies. Immunostainings were examined with a fluorescence microscopy. GFAP and IBA1 image analyses were performed using the ImageJ software (NIH, Bethesda, MD, USA).

\section{Histopathological examination}

The brain samples were collected, fixed in $4 \%$ formaldehyde solution, and embedded in paraffin. Individual 6$\mu \mathrm{m}$ sections were mounted on adhesive glass slides, dewaxed in xylene, and rehydrated in descending graded ethanol concentration for hematoxylin and eosin (H\&E) staining according to the previous protocol [6].

\section{Statistical analysis}

Data were expressed as the mean + SD unless otherwise specified. Statistical significance of the differences between each group was analyzed by Student's $t$ test or one-way analysis of variance (ANOVA) embedded in GraphPad Prism, version 7.0 (GraphPad Software Inc., La Jolla, CA, USA); $p<0.05$ was considered statistically significant, $p<0.01$ and $p<0.001$ indicated extremely significant differences.

\section{Results}

\section{E. coli infection upregulated the expression of miR-155} and miR-146a

Our previous miRNA transcriptional profiling of meningitic E. coli-infected astrocytes U251 showed that a number of miRNAs was differentially expressed upon E. coli infection. Among these miRNAs, miR-155 and miR-146a were found to be most significantly upregulated. Since miR-155 and miR-146a have been reported to be inflammation-associated molecules and $E$. coli infection can cause strong neuroinflammation, we therefore sought to explore their roles in meningitic $E$. coli-induced neuroinflammatory responses. First, we validated the expression of miR-155 and miR-146a in U251 cells stimulated by meningitic $E$. coli $\mathrm{PCN} 033$ for different times through real-time qPCR. The results revealed that miR-155 and miR-146a levels were significantly upregulated at $3 \mathrm{~h}$, which was the later period of E. coli infection (Fig. 1a, b). Expression of the pri-miRNA MIR155HG and pri-mir146a were in accordance with that of miR-155 and miR146a (Fig. 1c, d).
miR-155 and miR-146a were induced by the NF-KB signaling pathway

It has been widely reported that NF-KB and MAPK signaling pathways can regulate numerous important biological processes, including the biogenesis of miRNAs [15]. Considering that miR-155 and miR-146a are inflammation-associated miRNAs, we investigated whether these signaling pathways played roles in the regulation of miR-155 and miR-146a expression. We pretreated U251 cells with a set of specific inhibitors, including NF-kB (BAY-11072), JNK (SP600125), ERK1/2 (U0126), and p38 (SB202190), and then infected them with PCN033 for $3 \mathrm{~h}$. As shown in Figs. 2a and b, the $E$. coli infection-induced upregulation of miR-155 and miR-146a was completely prevented by BAY-11072, but SP600125 and U0126 had no inhibitory effect on the expression of these miRNAs. SB202190 only had a limited inhibitory effect on the expression of miR-146a but had no effect on miR-155 levels. In addition, we noticed above that the pri-miRNA MIR155HG and pri-mir-146a exhibited the synchronous changes with the mature miR-155 and miR-146a (Fig. 1), suggesting that the upregulation of miR-155 and miR-146a might occur at the transcriptional level. To evaluate the transcriptional regulation of miR-155, we analyzed the promoter region of miR-155 to predict the potential transcription factor binding sites by using PROMO [16] (http://alggen.lsi. upc.es/cgi-bin/promo_v3/promo/promoinit.cgi?dirDB= TF_8.3). Combined with the results showing that miR155 was modulated by NF-kB signaling pathways, we found an NF- $\mathrm{kB}$ binding site with high probability scores (Fig. 2c). As shown in Fig. 2d, the overexpression of p65 resulted in a concentration-dependent elevation of luciferase activity from the miR-155 promoter, but mutation of the NF- $\mathrm{KB}$ binding site significantly decreased miR155 promoter activity (Fig. 2e). Similarly, the promoter region of miR-146a was analyzed and two NF- $\mathrm{kB}$ sites were found (Fig. 2f). It was observed from Figs. $2 \mathrm{~g}$ and $\mathrm{h}$ that the overexpression of p65 enhanced the miR-146a promoter activity in a dose-dependent manner and the effect was abrogated by a mutation disturbing the two NF- $\mathrm{kB}$ element binding sites. Taken together, these results indicate that NF-KB signaling plays critical roles in the regulation of miR-155 and miR-146a by directly binding their promoters.

miR-155 and miR-146a inhibited E. coli-induced proinflammatory factors production and NF-KB signaling To investigate the potential role of miR-155 and miR$146 a$ in the response to $E$. coli infection, we assessed their effects on $E$. coli-induced inflammatory gene expression in astrocytes. Using the chemically synthesized mimics or inhibitors, we succeeded in up or downregulating the levels of miR-155 and miR-146a (Fig. 3a, b). 
A

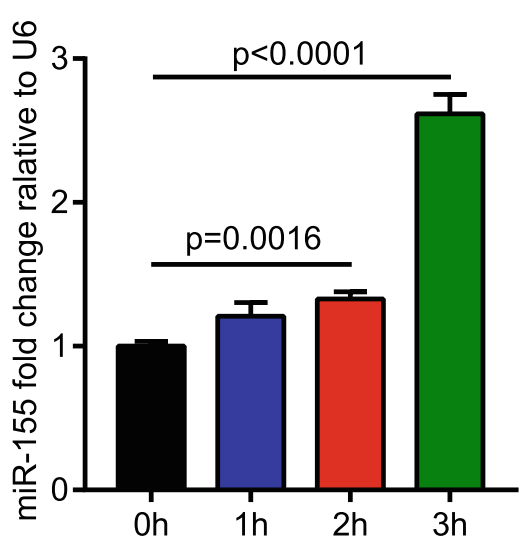

C

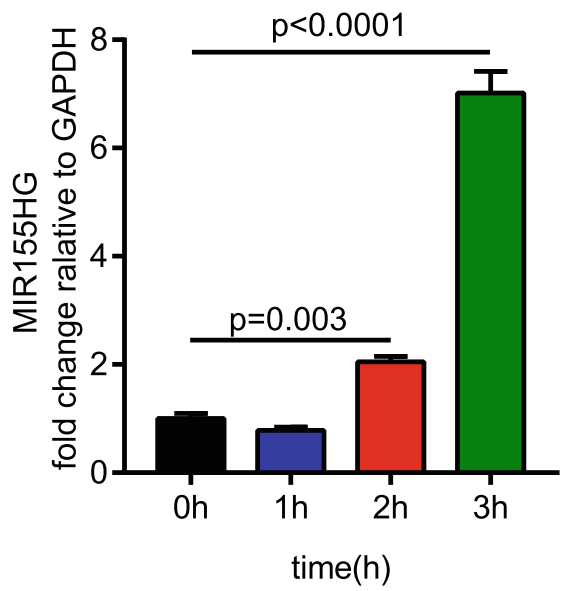

B
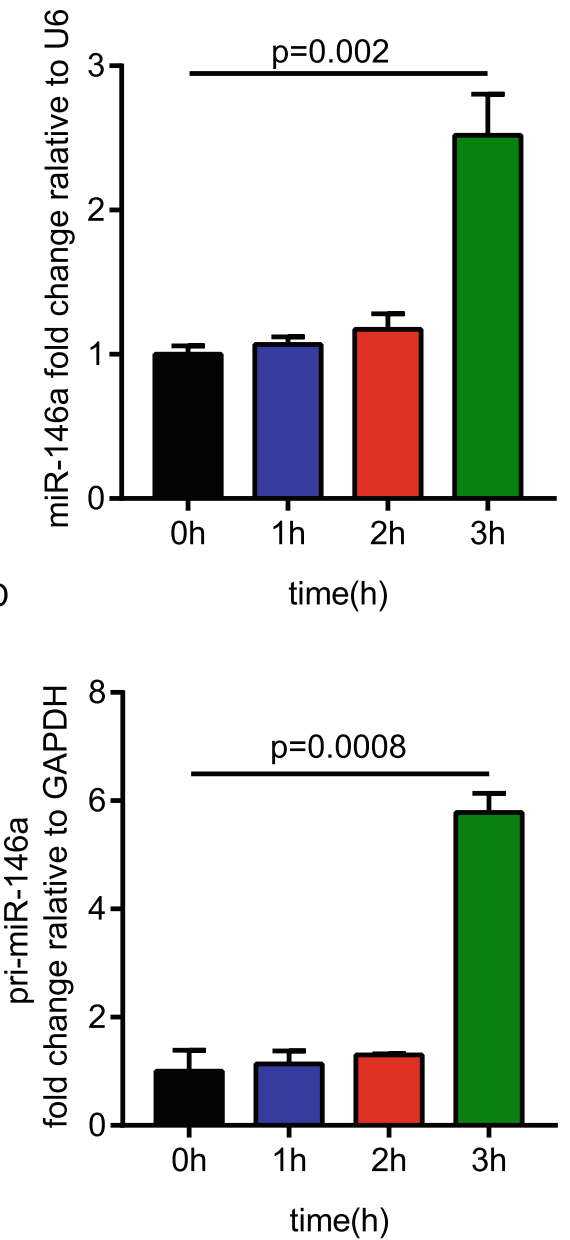

Fig. 1 Meningitic E. coli PCN033 infection upregulates miR-155, miR-146a, and their precursors in astrocytes U251. a and b The transcriptional expression of miR-155 and miR-146a in U251 cells in response to PCN033 infection at a multiplicity of infection (MOI) of 10. U6 was used as the reference control. $\mathbf{c}$ and $\mathbf{d}$ The transcriptional expression of MIR155HG and pri-miR-146a in U251 cells in response to PCN033 infection at an MOI of 10. GAPDH was used as the reference control. Data represent the mean + standard deviation (SD) ( $n=3 /$ group). Statistical analysis was carried out by one-way ANOVA. $p<0.05$ was considered statistically significant; $p<0.01$ and $p<0.001$ indicated extremely significant differences

We found that transfecting mimics and inhibitors of miR-155 and miR-146a had no influence on bacterial loads (Fig. 3c). Results showed that expression of the inflammatory cytokines IL-1 $\beta$, IL- 6 , and TNF- $\alpha$, as well as chemokines MCP-1 and MIP-2, were decreased after miR-155 or miR-146a mimics treatment (Fig. 3d). In contrast, the inhibitor of miR-155 or miR-146a increased these cytokines and chemokines (Fig. 3e). NF- кBmediated pro-inflammatory gene expression plays an important role in the innate immune response against bacterial infection. E. coli-infected astrocytes exhibited the time-dependent upregulation of NF-kB p65 subunit phosphorylation, whereas p-p65 was decreased at $3 \mathrm{~h}$, which was the timepoint that miR-155 and miR-146a were significantly increased (Fig. 4a). To determine whether miR-155 and miR-146a affect the NF-kB signaling pathway, we investigated their effects on phosphorylation of the p65 subunit in U251 cells. As shown in Figs. 4b and c, the infection-caused phosphorylation p65 in astrocytes transfected with miR155 or miR-146a mimics was significantly decreased compared with that in cells transfected with miR-ctrl. Moreover, transfection of the miR-155 or miR-146a inhibitor promoted the phosphorylation p65. In addition, using immunofluorescence microscopy, we observed p65 translocation from the cytoplasm to the nucleus upon E. coli infection, which could be partly prevented by the transfection of miR-155 or miR146a (Fig. 4d). These results showed that miR-155 and miR-146a play an inhibitory role in E. coli-induced pro-inflammatory factor production by negatively modulating NF- $\mathrm{kB}$ signaling. 
A

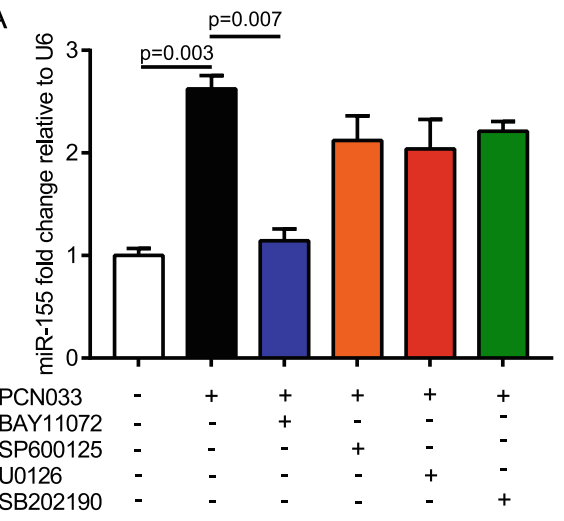

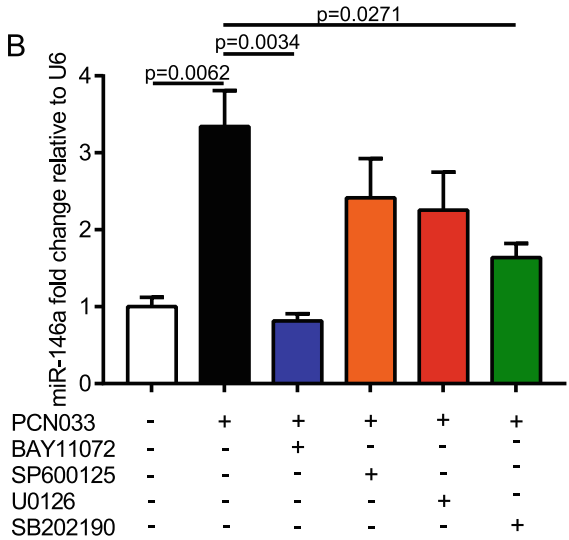

C

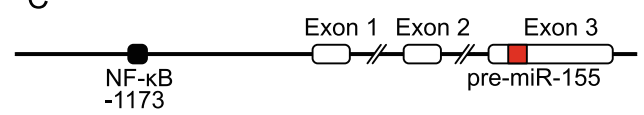

E

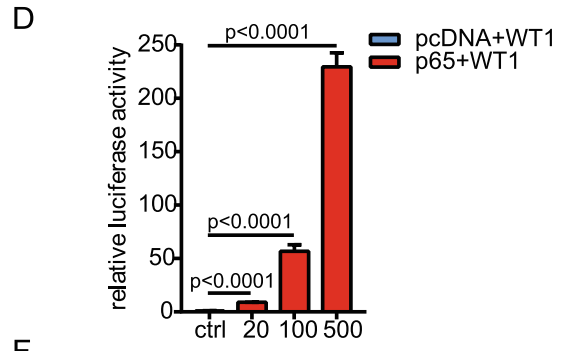

F

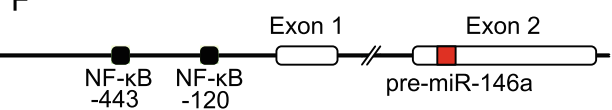

\section{$\mathrm{H}$}

G
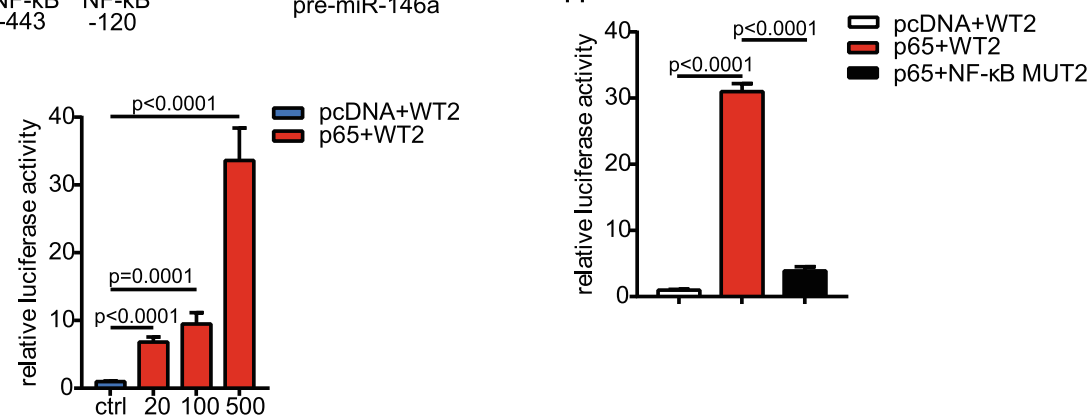

Fig. 2 Analysis of signaling pathways and transcription factors involved in regulation of miR-155 and miR-146a expression. a and $\mathbf{b}$ U251 cells were infected with PCN033 or mock-infected in the presence of BAY11072, SP600125, U0126, and SB202190. The expression of miR-155 and miR146a was detected by real-time qPCR. Data are presented as the mean + SD ( $n=3 /$ group). Statistical analysis was carried out by one-way ANOVA. c Schematic diagram of miR-155 genomic loci. A NF-KB binding site was predicted upstream of the MIR155HG transcription start site (+1). d Luciferase reporter assays were performed based on the co-transfection of a miR-155 promoter luciferase reporter (WT1), pRL-TK vector, and increasing concentrations of pcDNA3.1-p65 plasmid or empty vector control (pcDNA). Then, 24 h later, luciferase activity was measured, and the results were expressed as relative luciferase activity by normalizing firefly luciferase activity against Renilla luciferase activity, and results were recorded as the mean + SD from three replicate wells. e HEK-293T cells were co-transfected with a miR-155 promoter luciferase reporter or NF-KB mutation construct of the miR-155 promoter (NF-KB MUT1), along with pcDNA3.1-p65 plasmid. f Schematic diagram of miR-146a genomic loci. Two NF-KB binding sites were predicted upstream of the pri-miR-146a transcription start site (+1). g HEK-293T cells were co-transfected with a miR-146a promoter luciferase reporter (WT2), pRL-TK vector, and increasing concentrations of pcDNA3.1-p65 plasmid or empty vector control. $\mathbf{h}$ The miR-146a promoter luciferase reporter or NF-kB mutation construct of the miR-146a promoter (NF-kB MUT2), along with pcDNA3.1-p65 plasmid, were co-transfected into HEK-293T cells, and luciferase activity was measured. Error bars represented the SD calculated from the results of at least three independent experiments. Statistical analysis was carried out by one-way ANOVA. $p<0.05$ was considered statistically significant; $p<0.01$ and $p<0.001$ indicated extremely significant differences 


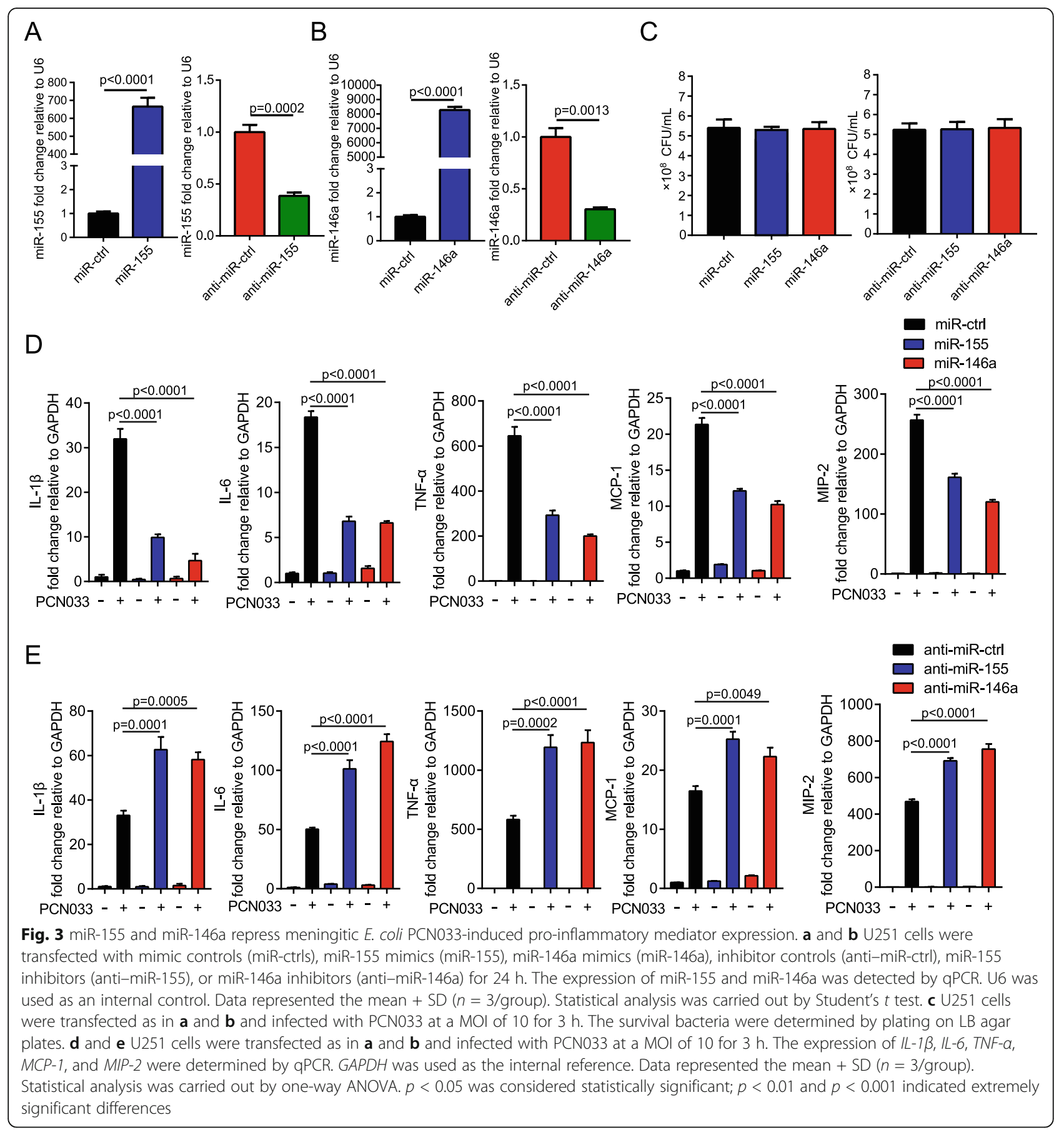

\section{TAB2 was the functional target of miR-155}

Generally, miRNAs exert their regulatory functions by modulating translation of their target genes by binding the 3' UTR of mRNA. Considering the results indicating that miR-155 can inhibit NF- $\mathrm{KB}$ activity, we first searched potential targets that are associated with inflammation. MiRNA target prediction software TargetScan showed that TAB2 had potential seed matches for miR-155. TAB2 is an adaptor molecule of the TLR/IL-1 signaling cascade that facilitates IL-1-dependent TNF receptor-associated factor 6 (TRAF6) ubiquitination and assembles the IL-1 signaling complex; thus, we further investigated the relationship between miR-155 and TAB2. A luciferase reporter carrying a putative binding site of the TAB2 3' UTR along with a mutant construct with 7-bp mutations in the seed region were generated (Fig. 5a), and the results shown in Fig. 5b indicated that the transfection of miR-155 significantly inhibited the luciferase activity of the wild-type TAB2 3' UTR construct but had no effect on the luciferase activity from the 


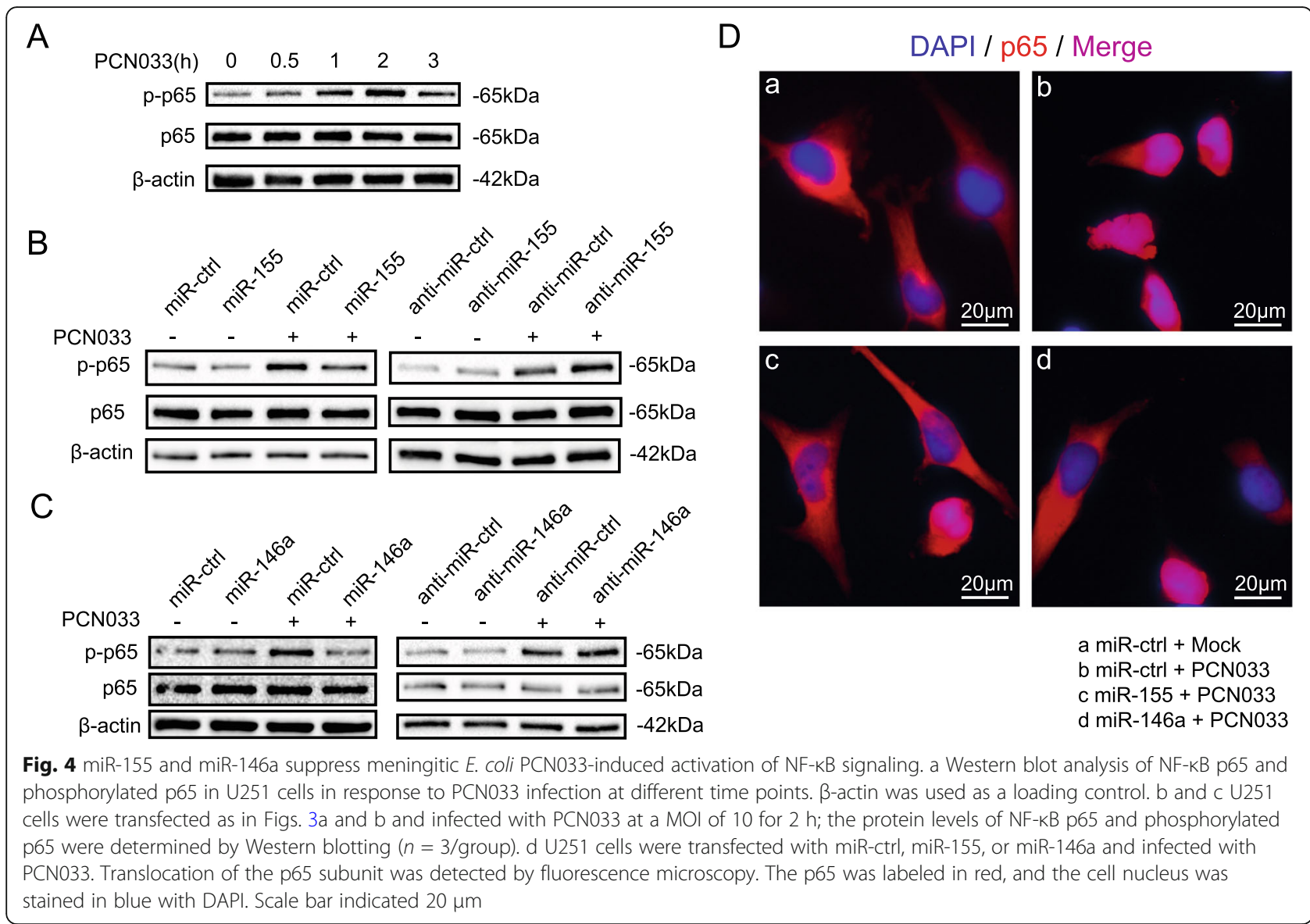

mutant construct. To further authenticate the negative correlation between miR-155 and TAB2, the expression of TAB2 was measured in U251 cells transfected with miR-155 mimics or inhibitors. As shown in Figs. 5c and $\mathrm{d}$, the overexpression of miR-155 significantly suppressed both mRNA and protein levels of TAB2, whereas the miR-155 inhibitor led to upregulated TAB2 mRNA and protein levels. In addition, the mRNA and protein expression of TAB2 were significantly downregulated in U251 cells upon E. coli infection (Fig. 5e, f), which was the opposite trend compared with that of miR-155. Moreover, we measured the protein level of TAB2 in U251 cells transfected with anti-miR-155 after E. coli infection. As shown in Fig. 5g, the E. coli infection-induced downregulation of TAB2 was restored by inhibiting miR-155, demonstrating that miR-155 can regulate TAB2 during $E$. coli infection. To further confirm that miR-155 exerts its effect through TAB2, we subsequently knocked down TAB2 in U251 cells using siRNA. As seen in Fig. 5h, TAB2 was successfully inhibited. As expected, the transfection of TAB2 siRNA resulted in decreased phosphorylation of NF-kB p65 upon E. coli infection compared with that with the transfection of siRNA control (Fig. 5i). Importantly, the augmented expression of inflammatory genes $(I L-1 \beta, I L$ 6, TNF- $\alpha, M C P-1$, and MIP-2) induced by the inhibition of miR-155 was decreased by suppressing TAB2 (Fig. 5j). Collectively, these results demonstrate that TAB2 is the functional target of miR-155.

\section{IRAK1 and TRAF6 were functional targets of miR-146a}

IRAK1 and TRAF6 have been reported to be important targets of miR-146a in monocytes and macrophages during the innate immune response [12, 17]. Since miR146 a was experimentally proven to be associated with meningitic E. coli infection, whether it also targeted IRAK1 and TRAF6 in astrocytes needed further investigation. Bioinformatic analysis showed that there are two binding sites in the IRAK1 3' UTR and three binding sites in the TRAF6 3' UTR (Fig. 6a). We found a significant decrease in luciferase activity in HEK-293T cells co-transfected with miR-146a mimics and the wild-type IRAK1 3' UTR luciferase reporter plasmid, and miR146a mimics still significantly downregulated the relative luciferase activity from the IRAK1-3' UTR-MUT2 construct but had mild effects on the IRAK1-3' UTR-MUT1 


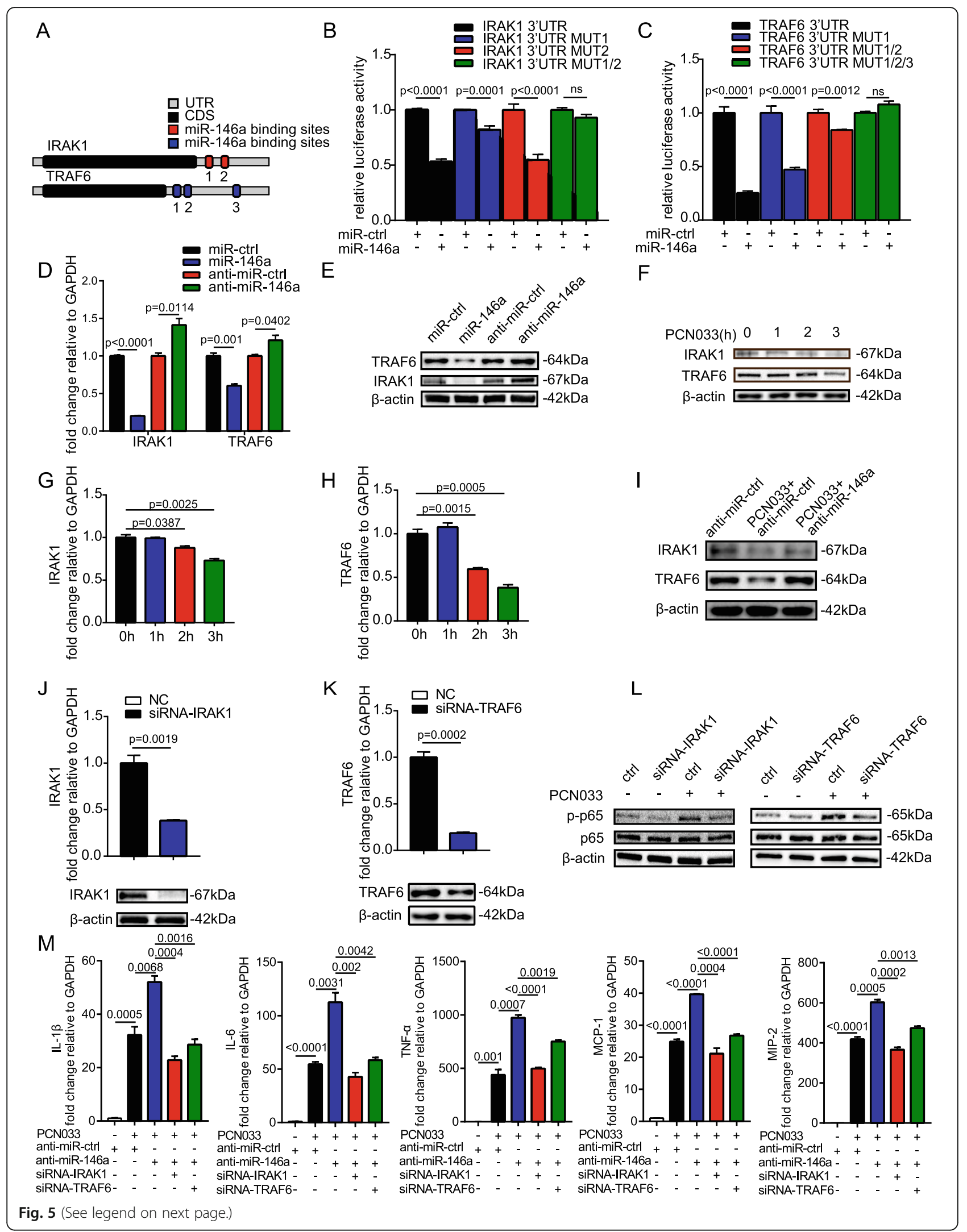


(See figure on previous page.)

Fig. 5 TAB2 is the functional target of miR-155. a Predicted miR-155 binding site in $3^{\prime}$ UTR of TAB2. Seven mutated nucleotides of the target site were indicated in red. $\mathbf{b}$ HEK-293T cells were co-transfected with miR-155 mimics or miR-ctrl, along with the wild-type or mutated TAB2 3' UTR luciferase reporter plasmid, and assessed for luciferase activity at $24 \mathrm{~h}$ after transfection. Relative luciferase activity was expressed as the Renilla luciferase activity normalized to firefly luciferase activity. $\mathbf{c}$ and $\mathbf{d}$ The mRNA and protein levels of TAB2 were determined in U251 cells after $24 \mathrm{~h}$ of transfection with miR-155, anti-miR-155, or their corresponding control oligonucleotides. e and $\mathbf{f}$ The mRNA and protein levels of TAB2 were determined in PCN033-infected U251 cells. g U251 cells were transfected with anti-miR-155 or anti-miR-ctrl and then infected with PCN033 for 3 $\mathrm{h}$. The expression of TAB2 was determined by Western blotting. $\mathbf{h}$ The mRNA and protein levels of TAB2 were determined in U251 cells after $24 \mathrm{~h}$ of transfection with siRNA-TAB2 or negative control (NC). i U251 cells were transfected with siRNA-TAB2 or NC and then infected with PCN033; the protein levels of NF-KB p65 and phosphorylated p65 were determined by Western blotting. $\mathbf{j}$ U251 cells were transfected with anti-miR-ctrl, anti-miR-155, or anti-miR-155, along with siRNA-TAB2, and then infected with PCN033 for $3 \mathrm{~h}$. The expression of IL-1 $\beta, I L-6, T N F-a, M C P-1$, and MIP2 was determined by qPCR. All data were represented as mean + SD ( $n=3 /$ group). Statistical analysis was carried out by Student's $t$ test or oneway ANOVA. $p<0.05$ was considered statistically significant; $p<0.01$ and $p<0.001$ indicated extremely significant differences

construct (Fig. 6b). This result showed that binding site 1 in the 3' UTR of IRAK1 is a vital targeting site of miR-146a. Similarly, we constructed a wild-type TRAF6 3' UTR luciferase reporter plasmid with a single site mutation, a double site mutation, and a triple site mutation. As shown in Fig. 6c, the overexpression of miR-146a markedly inhibited luciferase activity from the wild-type TRAF6 3' UTR luciferase reporter plasmid, whereas the suppression of luciferase activity was restored gradually in the presence of site mutations, revealing that all three binding sites play important roles in combination with miR-146a. In addition, overexpressing miR-146a significantly suppressed IRAK1 and TRAF6 expression in U251 cells, both at the mRNA and protein levels, whereas miR$146 \mathrm{a}$ inhibition led to the increased expression of IRAK1 and TRAF6 (Fig. 6d, e). We also measured the expression of IRAK1 and TRAF6 along with the E. coli infection and found that they were decreased in U251 cells upon infection (Fig. 6f-h). Moreover, miR146 a was determined to regulate the expression of IRAK1 and TRAF6 during E. coli infection (Fig. 6i). To further verify the function of miR-146a targets, we subsequently knocked down the expression of IRAK1 and TRAF6 at the mRNA and the protein levels (Fig. $6 j, k)$. As shown in Fig. 6l, the inhibition of both IRAK1 and TRAF6 reduced the phosphorylation of p65 induced by PCN033, as compared with that with their controls. Furthermore, inhibiting miR-146a promoted the expression of PCN033-induced inflammatory genes, including $I L-1 \beta, I L-6, T N F-\alpha, M C P-1$, and $M I P-2$, and these genes were notably reduced by interfering with IRAK1 or TRAF6 (Fig. 6m). Taken together, miR-146a exerts an inhibitory effect on inflammation by targeting IRAK1 and TRAF6. miR-155 and miR-146a targeted different molecules in the signaling cascade that downstream of TLR, including TAB2, IRAK1, and TRAF6, thereby collectively modulating the TLR-mediated inflammatory response.

\section{miR-155 and miR-146a collectively modulated EGFR-NF- $\mathbf{K B}$ signaling}

When we used bioinformatics tools to predict the targets of miR-155 and miR-146a, interestingly, we found that EGFR possibly combines with both miR-155 and miR146a. Moreover, our previous studies showed that EGFR contributes to bacterial-induced neuroinflammation by triggering the MAPK-ERK1/2 and NF- $\mathrm{KB}$ signaling pathways [18]. Thus, we investigated the regulative relationship between EGFR and miRNAs. Bioinformatics prediction showed that miR-155 and miR-146a contained respective binding sites for EFGR (Fig. 7a, c), and the overexpression of miR-155 or miR-146a inhibited luciferase expression from the wild-type EGFR 3' UTR. In contrast, the activity of luciferase constructs containing the mutant 3' UTR of EGFR was not inhibited by overexpressing miR-155 or miR-146a (Fig. 7b, d). In addition, miR-155 and miR-146a significantly decreased mRNA and protein levels of EGFR, whereas the inhibition of miR-155 or miR-146a promoted the expression of EGFR (Fig. 7e, f). Besides, U251 cells exhibited the significant downregulation of EGFR in response to meningitic $E$. coli infection (Fig. 7g, h). All these results suggested that EGFR is a potential target of miR-155 and miR-146a. To further investigate whether EGFR participates in the inflammatory process in response to $E$. coli infection, we pretreated U251 cells with 5,10 , or $20 \mu \mathrm{M}$ of the EGFR inhibitor AG1478 or DMSO as a control, and explored whether NF- $\mathrm{kB}$ signaling pathways were involved in the EGFR-mediated inflammatory response. Results showed that the p 65 phosphorylation induced by E. coli infection was notably attenuated by AG1478 in a dose-dependent manner (Fig. 7i), and correspondingly, as shown in Fig. 7 j, E. coli-induced IL-1 $\beta$, IL-6, TNF- $\alpha$, MCP-1, and MIP-2 expression was significantly suppressed by treatment with AG1478 in a dose-dependent manner. Taken together, these results indicated that EGFR is a target of miR-155 and miR-146a and that blocking EGFR activity could markedly alleviate downstream NF-kB signaling 


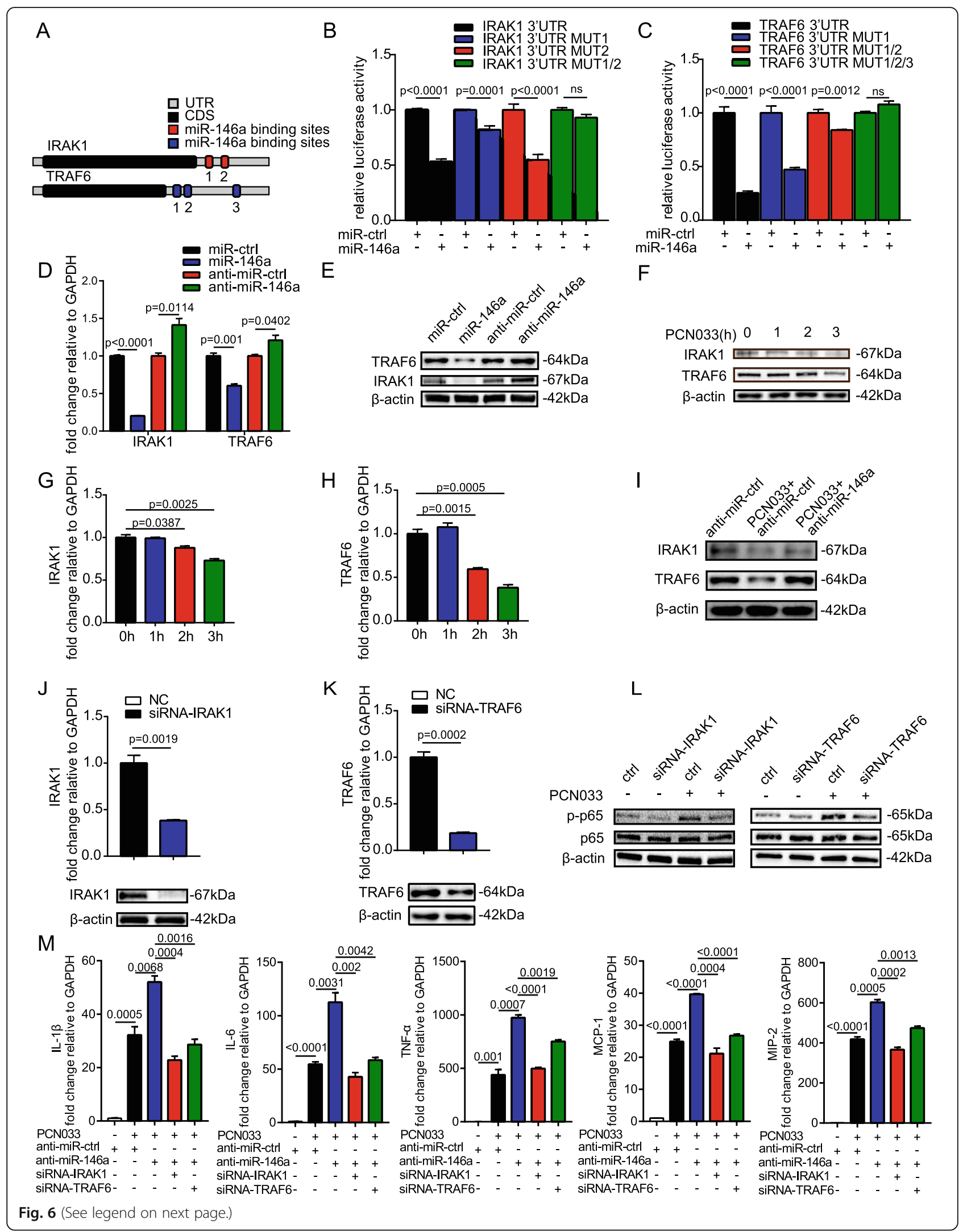




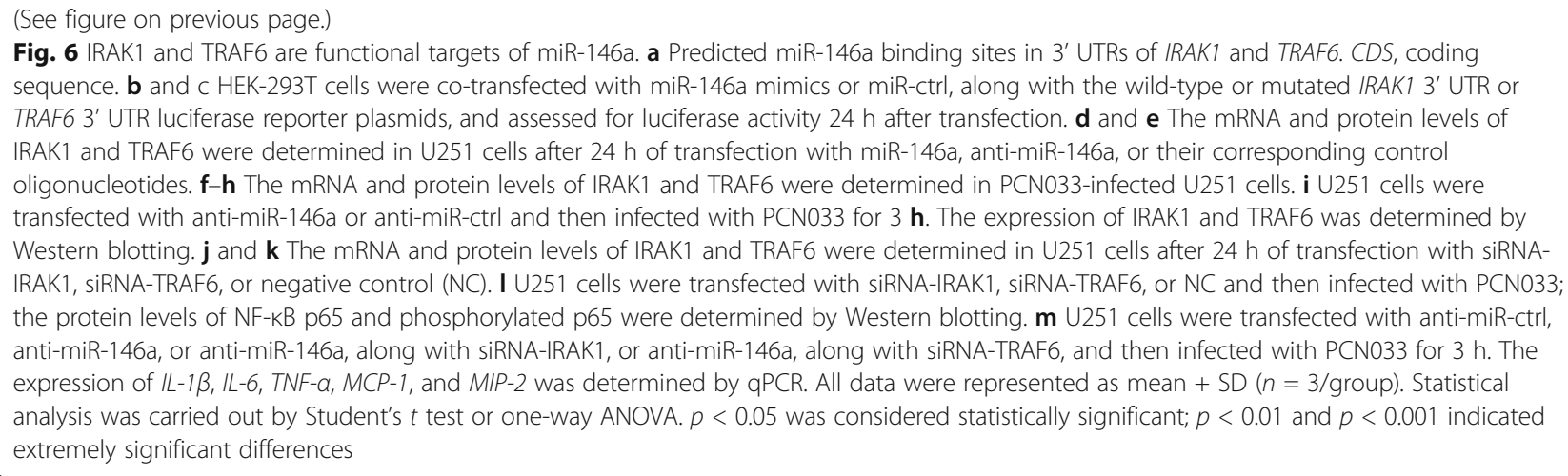

pathways, thus suppressing the production of proinflammatory cytokines and chemokines.

\section{Antagomir-155 and antagomir-146a aggravated inflammatory responses and reduced survival duration in E. coli-infected mice}

We further determined the effects of miR-155 and miR$146 a$ in $E$. coli-infected mice using chemically modified antisense oligonucleotides specific for miR-155 (antagomir-155) and miR-146a (antagomir-146a), which can cross the BBB into the CNS via i.v. routes [19-21]. Antagomir-155 and antagomir-146a were delivered to mice via the tail vein $24 \mathrm{~h}$ prior to PCN033 infection, and mice showed no signs of discomfort. At $6 \mathrm{~h}$ postchallenge, mice exhibited typical neurological signs including trembling, circling, paddling, and opisthotonos [6], at which time mice were sacrificed and brain tissues were collected. As shown in Figs. 8a and b, the injection of antagomir-155 significantly downregulated the expression of miR-155 induced by $E$. coli infection in mouse brains, and antagomir-146a also suppressed the level of miR-146a. Decreasing the expression of miR-155 and miR-146a did not affect the bacterial loads in blood and brains of challenged mice (Fig. 8c). Compared with levels in mice injected with antagomir-ctrl, inflammatory cytokines, and chemokines including IL- $1 \beta$, IL-6, TNF- $\alpha$, MCP-1, and MIP-2 were further enhanced at the transcription and protein levels by antagomir-155 and antagomir-146a treatment (Fig. 8d, e). These results indicated that miR-155 and miR-146a altered the inflammatory responses in respond to E. coli infection, which is not relevant to bacterial growth or survival. In addition, H\&E staining results showed that $E$. coli infection could induce meningeal thickening and neutrophil infiltration in the meninges, and these pathological phenomena were further exacerbated by treatment with antagomir-155 and antagomir-146a (Fig. 9a). Moreover, $E$. coli infection induced astrocytosis and microgliosis in mice, and these pathological phenomena were further exacerbated by antagomir-155 and antagomir-146a treatment (Fig. 9b-d). Based on these observations, we evaluated the effects of mir-155 and mir-146a on mouse lethality. As shown in Fig. 9e, the administration of antagomir-155 and antagomir-146a caused no significant changes in mouse mortality; however, the survival time was significantly decreased. In conclusion, inhibiting miR-155 and miR-146a in mice can further aggravate pro-inflammatory responses and lead to the reduced survival duration.

\section{Discussion}

Astrocytes are the most abundant glial cells within the brain and are essential for brain homeostasis and neuronal functions [22, 23]. Astrocytes play vital roles in regulating innate and adaptive immune responses in the injured CNS. Our previous study showed that the meningitis-associated E. coli strain PCN033 could infect astrocytes U251, induce rapid inflammatory responses, and promote the expression of many pro-inflammatory mediators such as IL- $1 \beta$, IL-6, IL- 8 , TNF- $\alpha$, MCP-1, and MIP-2. We hypothesized that astrocytes would trigger inflammatory responses to recruit circulating immune cells to the sites of insults, thereby mediating immune elimination of the pathogen. However, exaggerated or persistent long-term inflammatory responses lead to pathological neuroinflammation, and thus it is essential to tightly regulate the inflammatory response to avoid further damage of the CNS.

Increasing research has revealed that miRNAs are essential regulators of various biological processes, including inflammation $[24,25]$. Our previous comprehensive miRNA sequencing data showed that a group of miRNAs is differentially expressed upon PCN033 infection. Among these miRNAs, miR-155 and miR-146a exhibited the highest expression and were found to be the most significantly upregulated. Given that the regulatory role of miR-155 and miR-146a in the context of meningitic $E$. coli infection remained unknown, we selected these two molecules as targets for further experimentation. In this study, we demonstrated that miR-155 and miR-146a 


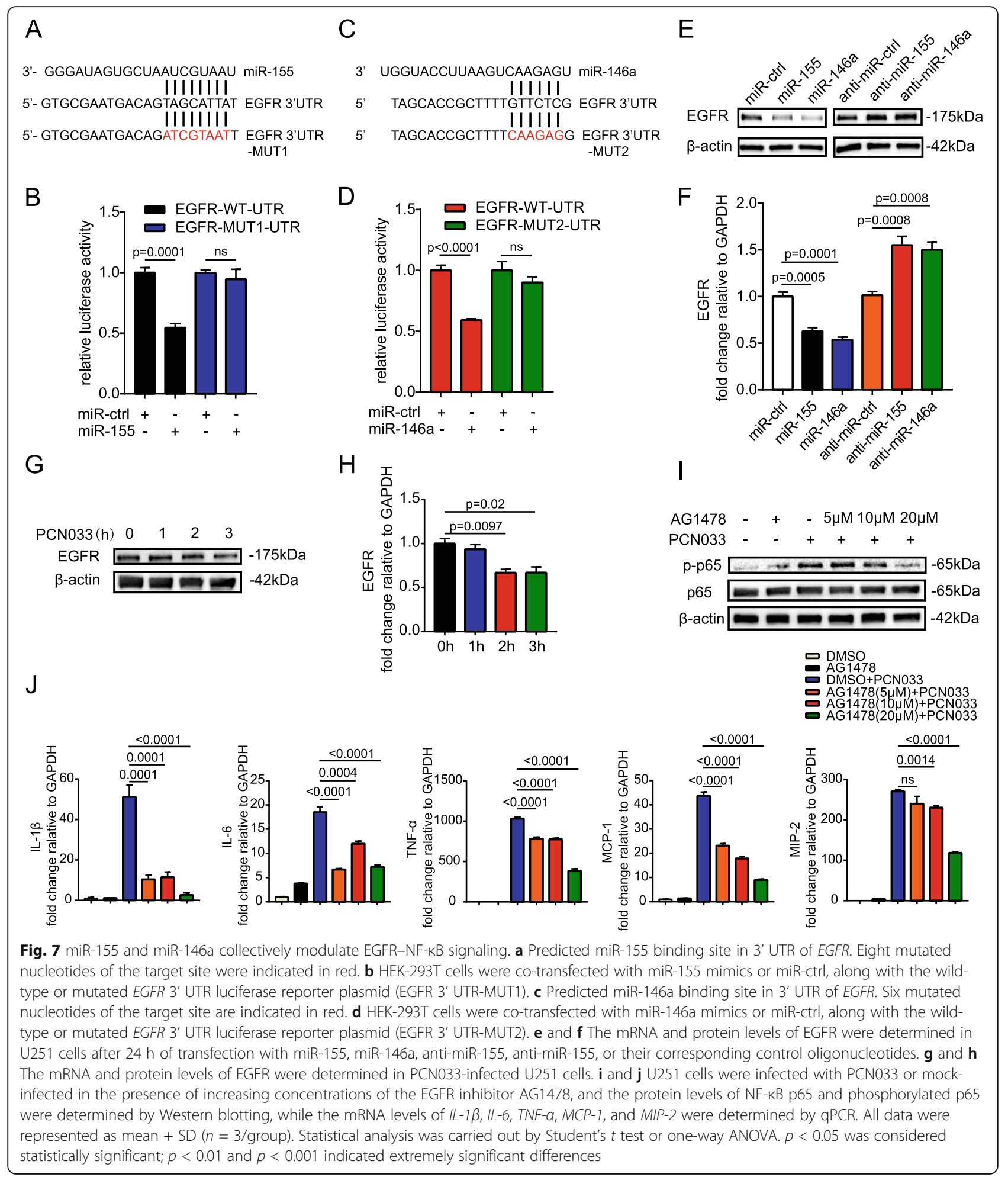

were highly upregulated by $E$. coli through NF- $\mathrm{kB}$ signaling and that miR-155 and miR-146a negatively regulated bacteria-induced pro-inflammatory responses. Importantly, we found that miR-155 combined with miR-146a to exert anti-inflammatory effects by targeting different key proteins in TLR signaling pathways and collectively regulate EGFR-NF- $\mathrm{kB}$ signaling.

TLRs play important roles in recognizing pathogens and initiating inflammatory responses during infection [26]. However, it is crucial to tightly modulate the TLR 


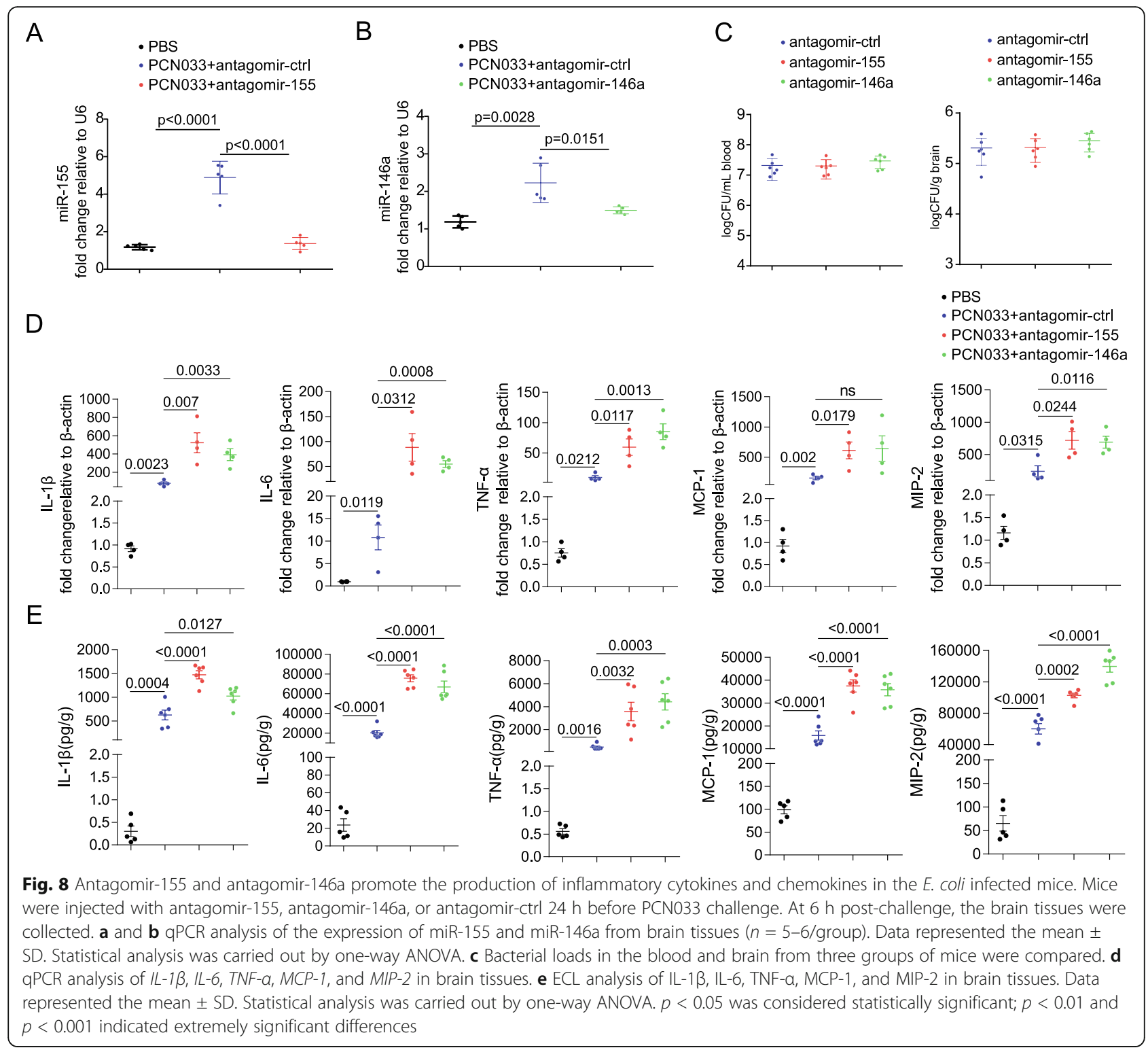

signaling pathways to avoid excessive inflammation. During this process, miRNAs can modulate the TLR signaling pathways by inhibiting key intracellular signaling proteins. A previous study and our work showed that miR-146a can inhibit IRAK1 and TRAF6. In addition, IRAK2, a kinase that is necessary for the persistence of NF- $\mathrm{kB}$ activation, has also been shown to be regulated by miR-146a [17]. In addition to miR-146a, miR-155 can target vital signaling proteins in TLR signaling pathways. MyD88 has been identified as a target of miR-155 in a model of Helicobacter pylori infection [27]. We also proved that TAB2 was an important target of miR-155. Moreover, Schulte et al. has verified that IKKE and NIK were targeted by miR-155 [28]. Consequently, miR-155 and miR-146a can work together to target different components of several TLR signaling pathways to avoid excessive pro-inflammatory responses. Besides, many miRNAs can also target signaling molecules in TLR pathways. For example, miR-302b suppressed bacteriainduced inflammatory responses by regulating IRAK4 [29]. The activity of NF- $\mathrm{KB}$ was tightly regulated by inhibitor of NF-KB kinases (IKKs), whereas IKK $\alpha$ was targeted by miR-223, and IKK $\beta$ was regulated by miR-199 [30, 31]. Further, many other miRNAs participated in the regulation of TLR signaling pathways through different mechanisms. Some miRNAs can directly modulate the expression of receptor expression. For example, let-7 miRNA family members let-7e and let-7i can regulate the expression of TLR4 $[32,33]$, and TLR3 and TLR4 expressions were regulated by miR-223 in granulocytes [34]. Some miRNAs can also target transcription factors to affect TLR-induced gene expression. For example, 


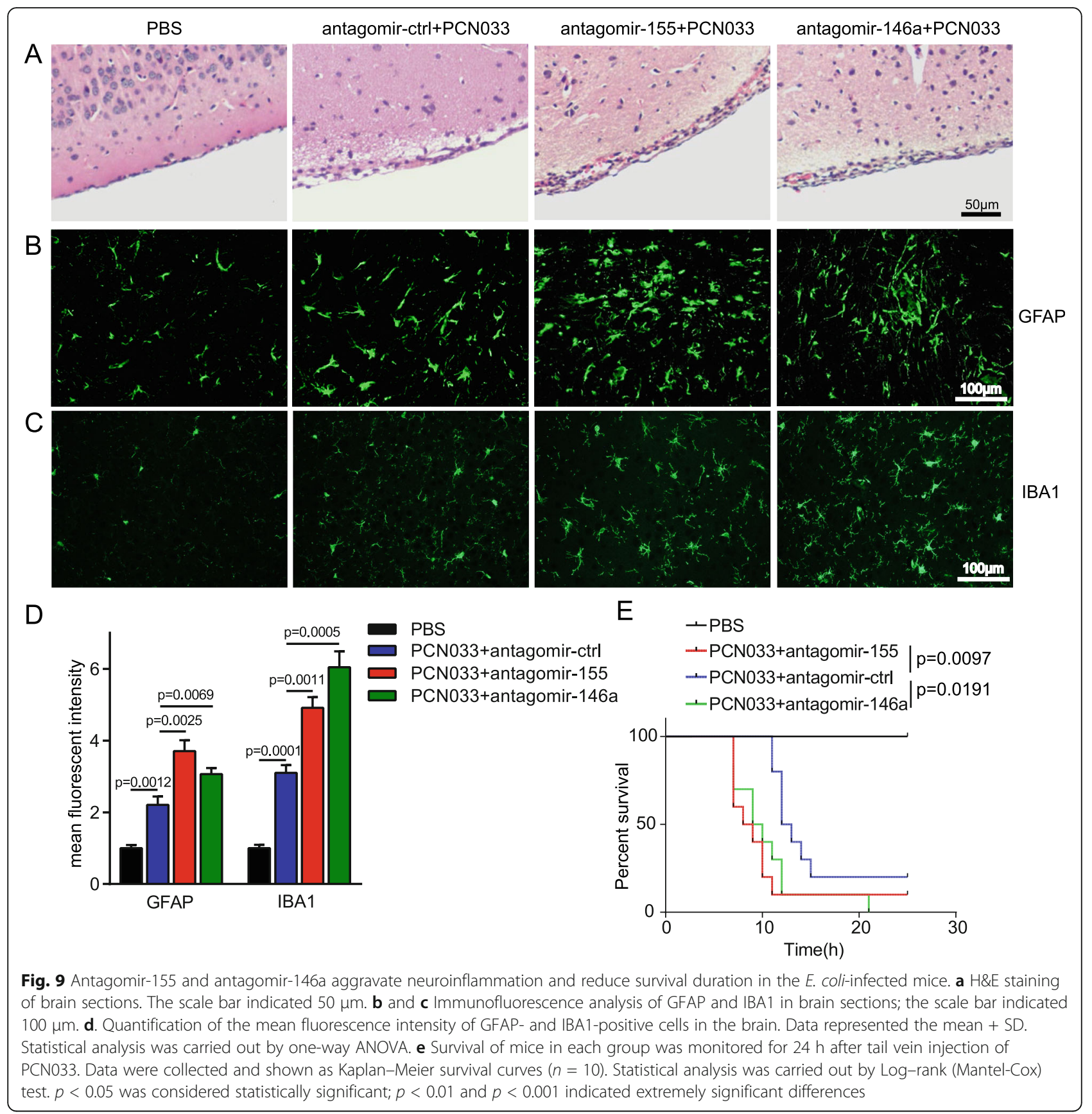

miR-155 targeted CEBPB to decrease G-CSF and IL-6 expression in splenocytes. Altogether, miRNAs could play crucial roles in controlling inflammation by inhibiting key proteins in the TLR signaling pathways.

EGFR is a member of the ErbB family, which is composed of four tyrosine kinase receptors, EGFR (ErbB1) and ErbB2-4 [35]. These four receptors are essential for modulating many biological processes, including cell survival, proliferation, and differentiation in many tissue types [36]. Despite the fact that EGFR has been mainly studied in the field of cancer, increasing studies have discovered diverse roles in pathogenic bacterial infections, such as regulating bacterial invasion, inflammation, and apoptosis [37-39]. Our recent research showed that the bacteria-induced transactivation of EGFR activated downstream signaling pathways $\mathrm{NF}-\kappa \mathrm{B}$ and MAPK-ERK1/2 in hBMECs, which subsequently initiated and mediated the inflammatory response. In this study, we blocked the function of EGFR by introducing the EGFR inhibitor AG1478 in astrocytes, resulting in the reduced expression of pro-inflammatory factors. This result suggests that EGFR also functions as an 
initiator of inflammatory responses in astrocytes. We further confirmed that NF- $\mathrm{KB}$ signaling pathways were influenced by EGFR activity. Importantly, we proved that EGFR was a common target of miR-155 and miR-146a, and thus, both can serve as anti-inflammatory miRNAs by targeting EGFR, subsequently inhibiting downstream NF- $\mathrm{kB}$ signaling pathways and eventually suppressing inflammatory cytokines and chemokines. EGFR has been reported as a target of miR-146a in cancer, and miR146a can block pancreatic cancer cell invasion and metastasis by inhibiting EGFR and IRAK1 [40]. To our knowledge, this is the first study to show that miR-146a and EGFR are implicated in bacterial infection and the related immune response and that EGFR is also a target of miR-155.

Our in vivo data showed that inhibiting miR-155 and miR-146a in mice promoted the production of inflammatory cytokines, aggravated astrocyte and microglia activation, and decreased mouse survival time. However, the bacterial loads in the blood and brain remained unchanged. We propose that miR-155 and miR-146a can modulate the inflammatory responses of mice to respond to $E$. coli infection, rather than exerting direct antibacterial activity. In this study, almost all E. colichallenged mice showed neurologic symptoms including trembling, circling, paddling, and opisthotonos. Besides, we observed the meningeal thickening and neutrophil infiltration in the meninges in response to the infection. Moreover, the production of pro-inflammatory cytokines and chemokines and the activation of astrocytes and microglia further supported the occurance of meningitis after hematogenous E. coli infection. Considering the important immunomodulation effects of miR-155 and miR-146a on E. coli-induced meningitis, miR-155 and miR-146a may be attractive candidates of new therapeutic interventions in the treatment of bacterial meningitis.

We found that miR-155 and miR-146a are simultaneously upregulated in astrocytes during the later period of $E$. coli infection. Therefore, a one-tier model was established in that NF-кB-regulated miR-155 and miR146a collectively act via feedback to modulate TLR signaling and EGFR-NF- $\mathrm{kB}$ signaling. In contrast to our results, Schulte [28] identified a two-tier mechanism in LPS-stimulated macrophages; specifically, miR-146 was found to be activated at sub-inflammatory levels, whereas miR-155 was gradually induced to full expression at pro-inflammatory levels. Therefore, miR-155 acts as a final limit to the inflammatory response once the miR-146-dependent barrier to LPS-induced inflammation has been breached. Interestingly, a recent study showed that miR-155 and miR-146a can form a combined positive and negative regulatory loop regulating NF-kB activity [41]. Inflammatory stimuli lead to the activation of NF- $\mathrm{kB}$, which rapidly activates miR-155. miR-155 acts as a positive regulator of NF- $\mathrm{kB}$ activity by inhibiting SHIP1 and SOCS1. As the inflammatory response develops, miR-146a levels accumulate to negatively regulate NF- $\kappa \mathrm{B}$ activity, resulting in the attenuation of inflammatory gene and miR-155 expression. In addition, another study on rheumatoid arthritis (RA) showed that miR-155 and miR-146a were downregulated in Tregs from RA patients, and the decrease in miR-146a-induced pro-inflammatory effects prevailed over the counteracting effect of reduced miR-155 expression, resulting in a pro-inflammatory phenotype for Tregs in RA [42]. It seems that miR-155 and miR-146a play different roles in controlling inflammatory responses in different disease models, depending on the diversity of cell types and experimental conditions. This also sheds light on the importance of understanding the interactions between them and the contribution of miR155 and miR-146a to specific inflammatory disorders.

\section{Conclusions}

In this study, we demonstrated the roles of miR-155 and miR-146a in the progress of meningitic $E$. coli infection. miR-155 and miR-146a were found to collectively regulate bacteria-triggered neuroinflammatory responses via negative feedback regulation of the TLR-mediated NF$\mathrm{\kappa B}$ and EGFR-NF- $\mathrm{kB}$ signaling pathways. Our findings might suggest potential therapeutic targets to combat bacterial infection in future.

\section{Abbreviations}

BBB: Blood-brain barrier; CNS: Central nervous system; E. coli: Escherichia coli; ECL: Electrochemiluminescence; ELISA: Enzyme-linked immunosorbent assay; FBS: Fetal bovine serum; IF: Immunofluorescence; IKK: Inhibitor of NF-KB kinase; LB: Luria-Bertani; miRNA: MicroRNA; PBS: Phosphate-buffered saline; SPF: Specific-pathogen-free; IL-1 13: Interleukin-1 beta; IL-6: Interleukin-6; TNFa: Tumor necrosis factor-alpha; MCP-1: Monocyte chemoattractant protein-1; MIP-2: Macrophage inflammatory protein-2; IRAK1: Interleukin 1 receptorassociated kinase 1; TRAF6: TNF receptor-associated factor 6; TAB2: TGF-betaactivated kinase 1 binding protein 2; EGFR: Epidermal growth factor receptor; NF-KB: Nuclear factor kappa B; MAPK: Mitogen-activated protein kinase; JNK: c-Jun N-terminal kinase; ERK: Extracellular regulated protein kinases; GAPDH: Glyceraldehyde-3-phosphate dehydrogenase; UTR: Untranslated region

\section{Acknowledgements}

We sincerely appreciated Prof. Shengbo Cao in Huazhong Agricultural University for kindly providing Astrocytes U251.

\section{Authors' contributions}

BY performed the experiments, analyzed the data, and drafted the manuscript. RY, BX, and JF participated in animal experiments. RY, XQ, and $L L$ helped to analyze the data. XW conceived of the project, coordinated and supervised the experiments, and revised the manuscript. XW, HC, CT, and MD provide technical and administrative support. The authors read and approved the final manuscript.

\section{Funding}

This work was supported by grants from the National Natural Science Foundation of China (31772736), the National Key R\&D Program of China (2016YFD0500406), the Outstanding youth project of Natural Science

Foundation in Hubei Province (2018CFA070), the Fundamental Research 
Funds for the Central Universities (Program No. 2662018PY032), and the earmarked fund for China Agriculture Research System (CARS-35).

\section{Availability of data and materials}

There is no data, software, databases, and application/tool available apart from the reported in the present study. All data are provided in manuscript.

\section{Declarations}

\section{Ethics approval and consent to participate}

The current study was carried out in accordance with the guidelines established by the China Regulations for the Administration of Affairs Concerning Experimental Animals (1988) and Regulations for the Administration of Affairs Concerning Experimental Animals in Hubei province (2005) (Project No.00270520 and Animal Welfare Assurance No. HZAUMO2019-030). All procedures and handling techniques were approved by the Committee for Protection, Supervision and Control of Experiments on Animals guidelines at Huazhong Agriculture University (SCXK2017-0012). All efforts were made to treat the experimental animals in this study ethically, and to minimize suffering.

\section{Consent for publication}

Not applicable

\section{Competing interests}

The authors declare that they have no competing interests.

\section{Author details}

${ }^{1}$ State Key Laboratory of Agricultural Microbiology, College of Veterinary Medicine, Huazhong Agricultural University, Wuhan, Hubei, China. ${ }^{2}$ Key Laboratory of Preventive Veterinary Medicine in Hubei Province, The Cooperative Innovation Center for Sustainable Pig Production, Wuhan, Hubei, China. ${ }^{3}$ Key Laboratory of Development of Veterinary Diagnostic Products, Ministry of Agriculture of the People's Republic of China, Wuhan, Hubei, China. ${ }^{4}$ International Research Center for Animal Disease, Ministry of Science and Technology of the People's Republic of China, Wuhan, Hubei, China.

Received: 14 January 2021 Accepted: 30 April 2021

Published online: 13 May 2021

\section{References}

1. Furyk JS, Swann O, Molyneux E. Systematic review: neonatal meningitis in the developing world. Trop Med Int Health. 2011;16(6):672-9. https://doi. org/10.1111/j.1365-3156.2011.02750.x.

2. Chang CJ, Chang WN, Huang LT, Huang SC, Chang YC, Hung PL, et al. Bacterial meningitis in infants: the epidemiology, clinical features, and prognostic factors. Brain Dev. 2004;26(3):168-75. https://doi.org/10.1016/S03 87-7604(03)00122-0.

3. Kim KS. Acute bacterial meningitis in infants and children. Lancet Infect Dis. 2010;10(1):32-42. https://doi.org/10.1016/S1473-3099(09)70306-8.

4. Kim KS. Human meningitis-associated Escherichia coli. EcoSal Plus. 2016;7(1) https://doi.org/10.1128/ecosalplus.

5. Sofroniew MV. Astrocyte barriers to neurotoxic inflammation. Nat Rev Neurosci. 2015;16(5):249-63. https://doi.org/10.1038/nrn3898.

6. Yang R, Liu W, Miao L, Yang X, Fu J, Dou B, et al. Induction of VEGFA and Snail-1 by meningitic Escherichia coli mediates disruption of the bloodbrain barrier. Oncotarget. 2016;7(39):63839-55. https://doi.org/10.18632/ oncotarget.11696.

7. Bartel DP. MicroRNAs: genomics, biogenesis, mechanism, and function. Cell. 2004;116(2):281-97. https://doi.org/10.1016/S0092-8674(04)00045-5.

8. Kurowska-Stolarska M, Alivernini S, Ballantine LE, Asquith DL, Millar NL, Gilchrist DS, et al. MicroRNA-155 as a proinflammatory regulator in clinical and experimental arthritis. Proc Natl Acad Sci U S A. 2011;108(27):11193-8. https://doi.org/10.1073/pnas.1019536108.

9. Cardoso AL, Guedes JR, Pereira de Almeida L, Pedroso de Lima MC. miR-155 modulates microglia-mediated immune response by down-regulating SOCS-1 and promoting cytokine and nitric oxide production. Immunology. 2012;135(1):73-88. https://doi.org/10.1111/j.1365-2567.2011.03514.x.

10. Pareek S, Roy S, Kumari B, Jain P, Banerjee A, Vrati S. MiR-155 induction in microglial cells suppresses Japanese encephalitis virus replication and negatively modulates innate immune responses. J Neuroinflammation. 2014; 11(1):97. https://doi.org/10.1186/1742-2094-11-97.

11. Ceppi M, Pereira PM, Dunand-Sauthier I, Barras E, Reith W, Santos MA, et al. MicroRNA-155 modulates the interleukin-1 signaling pathway in activated human monocyte-derived dendritic cells. Proc Natl Acad Sci U S A. 2009; 106(8):2735-40. https://doi.org/10.1073/pnas.0811073106.

12. Taganov KD, Boldin MP, Chang KJ, Baltimore D. NF-kappaB-dependent induction of microRNA miR-146, an inhibitor targeted to signaling proteins of innate immune responses. Proc Natl Acad Sci U S A. 2006;103(33):124816. https://doi.org/10.1073/pnas.0605298103.

13. Wang Z, Liu F, Wei M, Qiu Y, Ma C, Shen L, et al. Chronic constriction injuryinduced microRNA-146a-5p alleviates neuropathic pain through suppression of IRAK1/TRAF6 signaling pathway. J Neuroinflammation. 2018;15(1):179. https://doi.org/10.1186/s12974-018-1215-4.

14. Liu C, Zheng H, Yang M, Xu Z, Wang X, Wei L, et al. Genome analysis and in vivo virulence of porcine extraintestinal pathogenic Escherichia coli strain PCN033. BMC Genomics. 2015;16(1):717. https://doi.org/10.1186/s12864-01 5-1890-9.

15. Elton TS, Selemon H, Elton SM, Parinandi NL. Regulation of the MIR155 host gene in physiological and pathological processes. Gene. 2013;532(1):1-12. https://doi.org/10.1016/j.gene.2012.12.009.

16. Farre D, Roset R, Huerta M, Adsuara JE, Rosello L, Alba MM, et al. Identification of patterns in biological sequences at the ALGGEN server: PROMO and MALGEN. Nucleic Acids Res. 2003;31(13):3651-3. https://doi. org/10.1093/nar/gkg605.

17. Hou J, Wang P, Lin L, Liu X, Ma F, An H, et al. MicroRNA-146a feedback inhibits RIG-I-dependent type I IFN production in macrophages by targeting TRAF6, IRAK1, and IRAK2. J Immunol. 2009;183(3):2150-8. https://doi.org/10.4 049/jimmunol.0900707.

18. Yang XP, Fu JY, Yang RC, Liu WT, Zhang T, Yang B, et al. EGFR transactivation contributes to neuroinflammation in Streptococcus suis meningitis. J Neuroinflammation. 2016;13(1):274. https://doi.org/10.1186/s12 974-016-0734-0

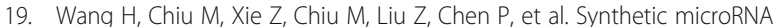
cassette dosing: pharmacokinetics, tissue distribution and bioactivity. Mol Pharm. 2012:9(6):1638-44. https://doi.org/10.1021/mp2006483.

20. Zhu B, Ye J, Nie Y, Ashraf U, Zohaib A, Duan X, et al. MicroRNA-15b modulates Japanese encephalitis virus-mediated inflammation via targeting RNF125. J Immunol. 2015;195(5):2251-62. https://doi.org/10.4049/jimmunol.1 500370.

21. Amjad N, Yang R, Li L, Fu J, Yang B, Xu B, et al. Decrease of miR-19b$3 p$ in brain microvascular endothelial cells attenuates meningitic Escherichia coli-induced neuroinflammation via TNFAIP3-mediated NFkappaB inhibition. Pathogens. 2019;8(4). https://doi.org/10.3390/pa thogens 8040268 .

22. Sofroniew MV, Vinters HV. Astrocytes: biology and pathology. Acta Neuropathol. 2010;119(1):7-35. https://doi.org/10.1007/s00401-009-0619-8.

23. Pekny M, Pekna M, Messing A, Steinhauser C, Lee JM, Parpura V, et al. Astrocytes: a central element in neurological diseases. Acta Neuropathol. 2016;131(3):323-45. https://doi.org/10.1007/s00401-015-1513-1.

24. Li Y, Shi X. MicroRNAs in the regulation of TLR and RIG-I pathways. Cell Mol Immunol. 2013;10(1):65-71. https://doi.org/10.1038/cmi.2012.55.

25. Baltimore D, Boldin MP, O'Connell RM, Rao DS, Taganov KD. MicroRNAs: new regulators of immune cell development and function. Nat Immunol. 2008;9(8):839-45. https://doi.org/10.1038/ni.f.209.

26. O'Neill LA. How Toll-like receptors signal: what we know and what we don't know. Curr Opin Immunol. 2006;18(1):3-9. https://doi.org/10.1016/j.coi.2 005.11.012.

27. Tang B, Xiao B, Liu Z, Li N, Zhu ED, Li BS, et al. Identification of MyD88 as a novel target of miR-155, involved in negative regulation of Helicobacter pylori-induced inflammation. FEBS Lett. 2010;584(8):1481-6. https://doi.org/1 0.1016/j.febslet.2010.02.063

28. Schulte LN, Westermann AJ, Vogel J. Differential activation and functional specialization of miR-146 and miR-155 in innate immune sensing. Nucleic Acids Res. 2013;41(1):542-53. https://doi.org/10.1093/nar/gks1030.

29. Zhou X, Li X, Ye Y, Zhao K, Zhuang Y, Li Y, et al. MicroRNA-302b augments host defense to bacteria by regulating inflammatory responses via feedback to TLR/IRAK4 circuits. Nat Commun. 2014;5(1):3619. https://doi.org/10.1038/ ncomms4619.

30. Li T, Morgan MJ, Choksi S, Zhang Y, Kim YS, Liu ZG. MicroRNAs modulate the noncanonical transcription factor NF-kappaB pathway by regulating 
expression of the kinase IKKalpha during macrophage differentiation. Nat Immunol. 2010;11(9):799-805. https://doi.org/10.1038/ni.1918.

31. Chen R, Alvero AB, Silasi DA, Kelly MG, Fest S, Visintin I, et al. Regulation of IKKbeta by miR-199a affects NF-kappaB activity in ovarian cancer cells. Oncogene. 2008;27(34):4712-23. https://doi.org/10.1038/onc.2008.112.

32. Androulidaki A, lliopoulos D, Arranz A, Doxaki C, Schworer S, Zacharioudaki $V$, et al. The kinase Akt1 controls macrophage response to lipopolysaccharide by regulating microRNAs. Immunity. 2009;31(2):220-31. https://doi.org/10.1016/j.jmmuni.2009.06.024.

33. Chen XM, Splinter PL, O'Hara SP, LaRusso NF. A cellular micro-RNA, let-7i, regulates Toll-like receptor 4 expression and contributes to cholangiocyte immune responses against Cryptosporidium parvum infection. J Biol Chem. 2007;282(39):28929-38. https://doi.org/10.1074/jbc.M702633200.

34. Muzio M, Bosisio D, Polentarutti N, D'Amico G, Stoppacciaro A, Mancinelli R, et al. Differential expression and regulation of toll-like receptors (TLR) in human leukocytes: selective expression of TLR3 in dendritic cells. J Immunol. 2000;164(11):5998-6004. https://doi.org/10.4049/jimmunol.164.11. 5998.

35. Olayioye MA, Neve RM, Lane HA, Hynes NE. The ErbB signaling network: receptor heterodimerization in development and cancer. EMBO J. 2000; 19(13):3159-67. https://doi.org/10.1093/emboj/19.13.3159.

36. Citri A, Yarden Y. EGF-ERBB signalling: towards the systems level. Nat Rev Mol Cell Biol. 2006;7(7):505-16. https://doi.org/10.1038/nrm1962.

37. Swanson KV, Griffiss JM, Edwards VL, Stein DC, Song W. Neisseria gonorrhoeae-induced transactivation of EGFR enhances gonococcal invasion. Cell Microbiol. 2011;13(7):1078-90. https://doi.org/10.1111/j.14625822.2011.01603.x

38. Frank CG, Reguerio V, Rother M, Moranta D, Maeurer AP, Garmendia J, et al. Klebsiella pneumoniae targets an EGF receptor-dependent pathway to subvert inflammation. Cell Microbiol. 2013;15(7):1212-33. https://doi.org/1 $0.1111 / \mathrm{cmi} .12110$.

39. Zhang J, Li H, Wang J, Dong Z, Mian S, Yu FS. Role of EGFR transactivation in preventing apoptosis in Pseudomonas aeruginosa-infected human corneal epithelial cells. Invest Ophthalmol Vis Sci. 2004;45(8):2569-76. https://doi.org/10.1167/iovs.03-1323.

40. Dominguez-Punaro Mde L, Segura M, Contreras I, Lachance C, Houde M, Lecours MP, et al. In vitro characterization of the microglial inflammatory response to Streptococcus suis, an important emerging zoonotic agent of meningitis. Infect Immun. 2010;78(12):5074-85. https://doi.org/10.1128/IAI. 00698-10.

41. Mann M, Mehta A, Zhao JL, Lee K, Marinov GK, Garcia-Flores Y, et al. An NFkappaB-microRNA regulatory network tunes macrophage inflammatory responses. Nat Commun. 2017;8(1):851. https://doi.org/10.1038/s41467-01700972-z.

42. Zhou Q, Haupt S, Kreuzer JT, Hammitzsch A, Proft F, Neumann C, et al. Decreased expression of miR-146a and miR-155 contributes to an abnormal Treg phenotype in patients with rheumatoid arthritis. Ann Rheum Dis. 2015; 74(6):1265-74. https://doi.org/10.1136/annrheumdis-2013-204377.

\section{Publisher's Note}

Springer Nature remains neutral with regard to jurisdictional claims in published maps and institutional affiliations.

Ready to submit your research? Choose BMC and benefit from:
- fast, convenient online submission
- thorough peer review by experienced researchers in your field
- rapid publication on acceptance
- support for research data, including large and complex data types
- gold Open Access which fosters wider collaboration and increased citations
- maximum visibility for your research: over 100M website views per year
At BMC, research is always in progress.
Learn more biomedcentral.com/submissions

